\title{
Effect of Indian Classical Instrumental Music on Stress and Anxiety in Male Medical Students
}

\author{
Prashant Bhatnagar ${ }^{1}$, Manju Lata Arya ${ }^{2}$ \\ ${ }^{1}$ Ph.D. Scholar, Department of Physiology, Rama Medical College, Hospital \& Research Center, Kanpur, Uttar \\ Pradesh, ${ }^{2}$ Professor, Department of Physiology, Rama Medical College, Hospital \& Research Center, Kanpur, \\ Uttar Pradesh
}

\begin{abstract}
Introduction: Medical professionals, especially medical students face a lot of stress and anxiety due to various challenges at personal and professional levels. Stress and anxiety affect their health and well-being and causes mental disturbance. Blood pressure, heart rate, and other biochemical parameters show an abnormal rise due to stress and anxiety. Music therapy using Indian classical instrumental music can help relieve this stress and anxiety and bring the biochemical parameters to normal levels.
\end{abstract}

Aim: The purpose of the present study was to evaluate the immediate and short term effects of Indian classical instrumental music on stress and anxiety using both qualitative and quantitative measurements on male medical students.

Materials and Method: Fifty-six (56) healthy male medical students aged between 17-25 years were selected from Rajkiya Medical College, Jalaun (Uttar Pradesh), for a month-long music therapy which included listening to Indian classical instrumental music every day for thirty minutes. ADSS questionnaire, salivary cortisol, blood pressure, heart rate, and lipid profile other required parameters were recorded twice, once at baseline and another after one month of music therapy.

Results: Post music therapy values revealed a significant decrease in ADSS score anxiety $(4.36 \pm 1.39 \mathrm{v} / \mathrm{s}$ $3.36 \pm 1.20 \mathrm{p}<0.0001)$, depression ( $3.14 \pm 1.70 \mathrm{v} / \mathrm{s} 2.23 \pm 1.50, \mathrm{p}<0.0001)$ Stress $(4.54 \pm 1.91 \mathrm{v} / \mathrm{s} 3.39 \pm 1.77$, $\mathrm{p}<0.0001)$ Salivary cortisol $(4.04 \pm 1.39 \mathrm{v} / \mathrm{s} 3.33 \pm 1.35, \mathrm{p}<0.0001)$. Further, a significant decrease was recorded in systolic blood pressure $(122.53 \pm 5.24 \mathrm{v} / \mathrm{s} 120.86 \pm 2.50, \mathrm{p} 0.0005)$ diastolic Blood Pressure $(82.75 \pm 5.36 \mathrm{v} / \mathrm{s} 80.82 \pm 1.74, \mathrm{p}=0.0045)$ and heart rate $(73.43 \pm 3.09 \mathrm{v} / \mathrm{s} 71.99 \pm 1.15, \mathrm{p}<0.0001)$.

Conclusion: The findings of the present study showed that listening to Indian classical instrumental music notably reduces salivary cortisol, blood pressure, heart rate, respiration rate, blood glucose, and lipid profile, and helps to relieve stress and anxiety in male medical students. However, further studies on a larger population are required to make a general policy to facilitate the better mental health of medical students.

Keywords: Stress, anxiety, young male medical students, music therapy.

\section{Introduction}

Stress is an excessive and acute fear and worry about

\section{Corresponding Author:}

Prashant Bhatnagar

Assistant Professor, Department of Physiology, Rajkiya

Medical College, Jalaun, Orai, Uttar Pradesh

e-mail: prashantbhatnagar06@gmail.com

Phone Number: 8881309383 anything. Anxiety occurs in response to stress. ${ }^{(1)}$ When a body suffers stress, it responds to it through physical, physiological or mental adaptation. ${ }^{(2)}$ Many chronic and acute diseases are triggered by stress. It is also seen that stress acts as a cause for many cardiovascular diseases, and sometimes gives rise to fatal diseases like cancer. (3-5) In response to stress and anxiety in human body, the level of blood pressure ${ }^{(6)}$, heart rate ${ }^{(7)}$, respiration rate ${ }^{(8)}$, Salivary cortisol (9), blood sugar ${ }^{(10)}$ and lipid profile ${ }^{(11)}$ increase. 
In medical students, stress level is higher as compared to students of other profession because of the medical field, and this stress level keep on increasing throughout the course in medical college. ${ }^{(12,13)}$ A number of stressors have been found to affect the well-being of medical students and they often result in psychological morbidities like depression and anxiety. ${ }^{(14)}$ In a selfexecuted, questionnaire-based study, it was found that $39.1 \%$ medical students were distressed, $15.6 \%$ were suffering from anxiety, and around $12 \%$ were found to be depressed. ${ }^{(15)}$

Music helps in lowering anxiety and elevating mood. It also affects various physiological and biochemical factors such as blood pressure, pulse rate, respiration rate, lipids profile and blood sugar levels. ${ }^{(16)}$ Indian classical instrumental music has been found to relieve stress in gastroscopy patients. ${ }^{(17)}$ Indian raga improves attention and concentration in college students. ${ }^{(18)}$

However, the effects of Indian classical instrumental music on stress and anxiety of male medical students are still unclear, hence the present study was conducted to assess the effect of Indian classical music on stress and anxiety in male medical students.

\section{Material and Method}

Participants: The current interventional type of study included fifty-six (56) male medical students from Rajkiya Medical College, Jalaun (UP). This study took place in the Department of Physiology. The inclusion criteria included a healthy first-year M.B.B.S. male students aged between 17-25 years. Students who were diagnosed with any medical disorders; undergoing medical treatment; having a dislike for music and preferred not to listen to it; suffering from severe anxiety and major depressive disorder; undergoing any Complimentary and Alternative Medicine (CAM's) were excluded from the study.

Pre and post music therapy the following parametersADSS questionnaire, salivary cortisol, blood pressure, heart rate, respiration rate, fasting blood sugar and lipid profile, were recorded. All the participants were made aware in detail about the objectives of the study. Informed written consent was taken from all the subjects that ensured that the participants could make an informed, voluntary and rational decision to participate. A demographic questionnaire was filled by them to gather information about their age, weight, and height. Psychological health, i.e., the overall level of stress and anxiety in the subjects was measured by using responses to self-reported measures through the ADSS test questionnaire. ${ }^{(19)}$

Measurements: All of the physiological and biological parameters were recorded and calculated. These parameters were taken before noon. For salivary cortisol, the circadian fluctuations of hormone levels are pronounced in the morning hours and flatten throughout the day. ${ }^{(20,21)}$

Music Intervention: Music therapy was started for all the students after recording pre-music therapy parameters. All the subjects were asked to come at 7:30 $\mathrm{am}^{(22)}$ sharp in a hall with a capacity of 60 to 70 persons. The hall was properly ventilated and isolated from noisy gathering places and distracting sounds, to provide easy access to all the subjects. Once settled on respective chairs from 7:30 am to 7:40 am, participants were asked to relax and make themselves comfortable. After 10 minutes, i.e., at 7:50 am, the Indian classical instrumental music (Raga Desi-Todi played on a flute by a renowned Indian musician, Pt. Hari Prasad Chaurasia) ${ }^{(23)}$ was played by the attendants for the next 30 minutes $^{(23,24)}$ at 50 to $60 \mathrm{DB} .{ }^{(25)}$ All the subjects were advised to keep their eyes closed during music therapy. ${ }^{(25)}$

Half an hour later, at 8:20 am, the music was stopped and the candidates were allowed to leave the room. This therapy took place in the same manner for a month. ${ }^{(23)}$ On the fifteenth and the thirtieth day of music therapy, all the candidates were asked feedback about how they felt during the therapy. Students were free to contact for guidance if they had some queries or felt uneasy.

Parameters: Cortisol: For the analysis of cortisol, saliva was collected using small cotton swabs. Participants were given cotton roll to gently chew for 1 minute. After one minute, the stimulated saliva sample was collected by taking the chewed cotton roll and placing it into a small plastic tube. Saliva was analyzed by cortisol ELISA kit by BioVision, and this was conducted between 12:00 to 17:00 hours, to minimize the confounding effect of the hormonal diurnal rhythm. ${ }^{(26)}$

Blood pressure: Blood pressure was measured by the auscultatory method using a Sphygmomanometer. ${ }^{(27)}$

Heart Rate: Heart rate was recorded from the radial pulse. $^{(28)}$

Respiration Rate: In the resting condition, the 
respiration rate was calculated by counting the number of chest-rise per minute. ${ }^{(29,30)}$

Glucose level: It was estimated by the fasting method by the GOD-POD method. ${ }^{(30)}$

Lipid Profile: Lipid profile in the serum sample was measured by serum concentrations of the following parameters:

The serum concentration of total cholesterol was estimated by the enzymatic CHOD-POD method. ${ }^{(30)}$

The serum concentration of triglycerides was calculated by the GPO-PAP method. ${ }^{(30)}$

The serum concentration of high-density lipoprotein was measured by CHOD-POD/Phosphotungstate method. ${ }^{(30)}$
The serum concentration of low-density lipoprotein was evaluated by using Friedewald's formula: LDL cholesterol $=$ total cholesterol - HDL cholesterol [triglycerides/5]. ${ }^{(31)}$

Statistical Analysis: Outcomes were expressed as Mean \pm SD (standard deviation of the mean). The statistical data were analyzed and compiled using SPSS 21st version software manufactured by IBM USA. To compare values obtained before and after the musical intervention, the student's paired t-test was applied. A $\mathrm{p}$-value $<0.05$ was considered significant.

\section{Results}

Results of the present study included data of various parameters in all the participants before and after music intervention. For all given parameters, degree of freedom: 55, 95\% confidence interval was considered.

Table 1: ADSS scores pre music therapy and post music therapy.

\begin{tabular}{|l|c|c|c|}
\hline & Pre Music Therapy & Post Music Therapy & p-value \\
\hline Anxiety (0-9) & $4.36 \pm 1.39$ & $3.36 \pm 1.20$ & $<0.0001^{* *}$ \\
\hline Depression (0-9) & $3.14 \pm 1.70$ & $2.23 \pm 1.50$ & $<0.0001^{* *}$ \\
\hline Stress (0-9) & $4.54 \pm 1.91$ & $3.39 \pm 1.77$ & $<0.0001^{* *}$ \\
\hline
\end{tabular}

Values expressed as Mean+/-SD. **highly significant.

The level of anxiety, depression, and stress ranges from 0-9. Above 9, the condition is severe.

Table 1 suggests that mean ADSS score for anxiety $(4.36 \pm 1.39 \mathrm{v} / \mathrm{s} 3.36 \pm 1.20), \mathrm{p}<0.0001$ depression $(3.14 \pm$ $1.70 \mathrm{v} / \mathrm{s} 2.23 \pm 1.50), \mathrm{p}<0.00001$ and stress $(4.54 \pm 1.91 \mathrm{v} / \mathrm{s} 3.39 \pm 1.77), \mathrm{p}<0.0001$ was significantly decreased in male medical students after participating in music therapy for one month.

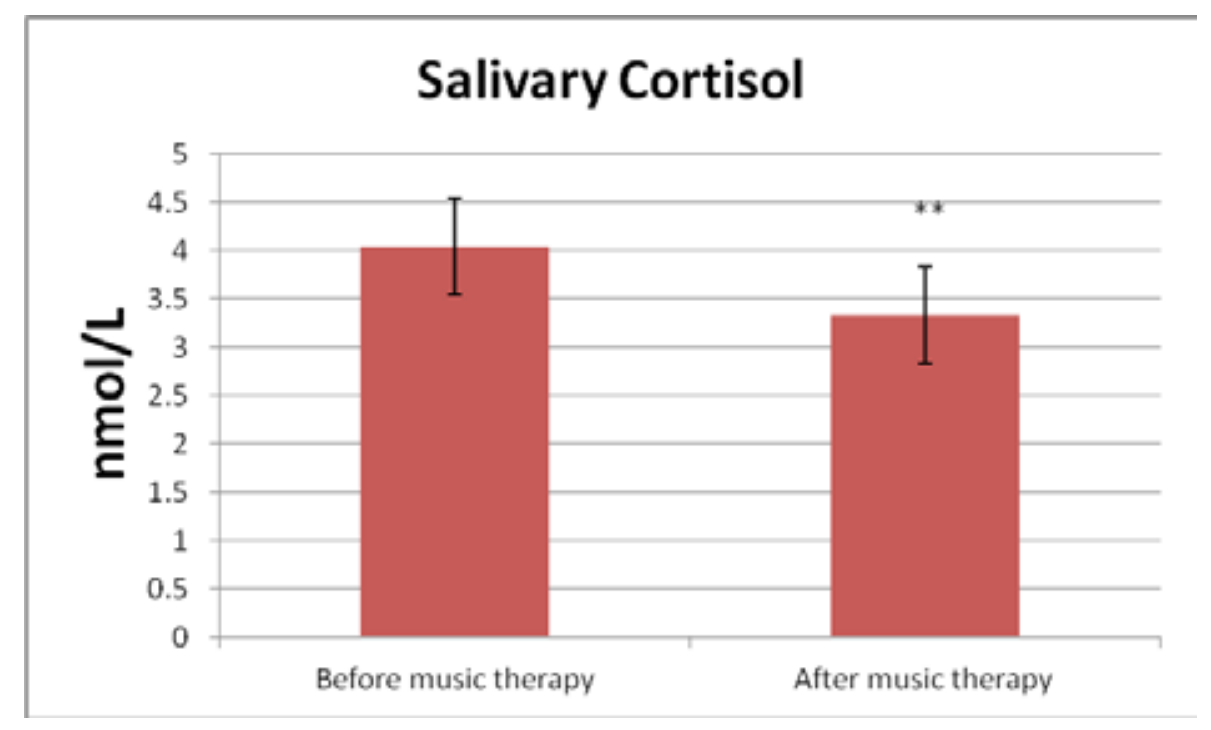

$* * \mathrm{p}<0.0001$ Highly significant

Figure 1. Mean difference in salivary cortisol pre music therapy and post music therapy. 
It is evident from Figure 1 that the baseline values of salivary cortisol significantly depleted from $4.04 \pm 1.39 \mathrm{nmol} / \mathrm{L}$ to $3.33 \pm 1.35 \mathrm{nmol} / \mathrm{L}(\mathrm{p}<0.0001)$ in male medical students post music therapy a month later.

Table 2: Blood pressure pre music therapy and post music therapy

\begin{tabular}{|l|c|c|c|}
\hline Parameter & Pre Music Therapy & Post Music Therapy & p-value \\
\hline SBP $(\mathrm{mmHg})$ & $122.53 \pm 5.24$ & $120.86 \pm 2.50$ & $0.0005^{* *}$ \\
\hline DBP $(\mathrm{mmHg})$ & $82.75 \pm 5.36$ & $80.82 \pm 1.74$ & $0.0045^{* *}$ \\
\hline
\end{tabular}

Values expressed as Mean+/-SD. $\mathrm{SBP}=$ systolic blood pressure, $\mathrm{DBP}=$ diastolic blood pressure, $* *$ highly significant

Further, A significant decrease in systolic blood pressure from $122.54 \pm 5.24 \mathrm{mmHg}$ to $120.86 \pm 2.50$ $\mathrm{mmHg}(\mathrm{p}=0.0005)$ and diastolic blood pressure from
$82.75 \pm 5.36 \mathrm{mmHg}$ to $80.82 \pm 1.74 \mathrm{mmHg}(\mathrm{p}=0.0045)$ was recorded after one month musical therapy. (Table 2 ).

Table 3: Heart rate, respiration rate and fasting blood sugar pre music and post music therapy

\begin{tabular}{|l|c|c|c|}
\hline Parameter & Pre Music Therapy & Post Music Therapy & p-value \\
\hline HR(beats/min) & $73.43 \pm 3.09$ & $71.98 \pm 1.15$ & $<0.0001^{* *}$ \\
\hline RR(/min) & $14.46 \pm 1.94$ & $12.64 \pm 0.94$ & $<0.0001^{* *}$ \\
\hline FBS(mg/dL) & $91.61 \pm 10.35$ & $87.32 \pm 8.69$ & $<0.0001^{* *}$ \\
\hline
\end{tabular}

Values expressed as Mean+/-SD. **highly significant. HR=heart rate, RR=respiration rate, FBS= fasting blood sugar

Table 3 shows a significant reduction in heart rate, respiration rate and fasting blood sugar post music therapy. There was a significant decrease of $1.45 \pm 1.94$ beats/min, $(\mathrm{p}<0.0001), 1.82 \pm 1.00 / \mathrm{min},(\mathrm{p}<0.0001)$ and
$4.29 \pm 2.66 \mathrm{mg} / \mathrm{dL},(\mathrm{p}<0.0001)$ in heart rate, respiration rate and fasting blood sugar respectively in male medical students after month-long music therapy.

Table 4: Lipid profile pre music therapy and post music therapy.

\begin{tabular}{|l|c|c|c|}
\hline Parameter & Pre Music Therapy & Post Music Therapy & p-value \\
\hline TC(mg/dL) & $199.33 \pm 33.54$ & $198.98 \pm 33.42$ & $<0.0001^{* *}$ \\
\hline TG(mg/dL) & $115.44 \pm 24.49$ & $114.16 \pm 24.91$ & $<0.05^{*}$ \\
\hline HDL $(\mathrm{mg} / \mathrm{dL})$ & $45.96 \pm 6.43$ & $46.66 \pm 6.50$ & $<0.0001^{* *}$ \\
\hline LDL $(\mathrm{mg} / \mathrm{dL})$ & $128.88 \pm 30.09$ & $128.53 \pm 30.04$ & $<0.0001^{* *}$ \\
\hline
\end{tabular}

Values expressed as Mean+/-SD. *significant ** highly significant. TC=total cholesterol, TG=triglycerides, HDL= high-density lipoprotein, $\mathrm{LDL}=$ low-density lipoprotein.

Further, a significant decrease of $\mathrm{TC}(\mathrm{p}<0.0001)$, TG $(p<0.0001)$ and LDL $(p<0.0001)$ was observed in all the participants after following one month music therapy. On the other hand, a significant increase of 0.69 $\pm 0.1 \mathrm{mg} / \mathrm{dL}$ with a $\mathrm{p}$-value $<0.0001$ was recorded in post HDL value compare to pre HDL value. A decrease in TG with a p-value of 0.05 was recorded.(Table 4)

\section{Discussion}

Stress is a general response of the body to any mental or physical pressure on it. ${ }^{(32,33)}$ Stress is a condition or a feeling that one experiences upon the realization that the expectations from him/her overshadow the social as well as personal potentiality and resources the individual 
can put forth." (34) Anxiety, on the other hand, acts as a response to stress both in moderation and in excess. In moderation, stimulates an anticipatory and adaptive response; and if it exceeds, it will destabilize and dysfunction the individual. ${ }^{(35,36)}$ Although anxiety is as familiar and probably as devitalizing as depression, (37) it has managed to achieve less recognition and is often unseen and undertreated in the general population. (38)

Indian medical students suffer more stress and anxiety than other professionals. $(39,40)$ This is also because the Indian medical education system is slightly different from other regions, especially because of its selection process. ${ }^{(41)}$ Moreover, the influence of one's family in deciding the career in the medical field too plays a role in growing stress, anxiety and depression in Indian medical students. ${ }^{(39,42)}$ Furthermore, Indian medical students rarely seek professional help, mostly because of embarrassment and taboo concerning mental health. ${ }^{(43)}$

The present study recorded a significant decrease in the ADSS score of anxiety, depression, and stress in male medical students after following one month of music therapy. The results of the current study were very similar to the findings of the previous study of Prakash K et al. ${ }^{(44)}$ as they revealed that the music therapy made the subjects feel less stressed and anxious. These significant changes of ADSS score in all three parameters seem to be due to one-month music therapy as a prior study suggests that listening to the music may have increased the HPA axis activation and assisted the faster recovery of the ANS, which further reduced stress and anxiety in the subjects. ${ }^{(16)}$

Further, a significant decrease in salivary cortisol was observed in the present study. These findings are very similar to the earlier studies of YC Hou et al (45) and Shaji John et al. ${ }^{(46)}$ YC Hou et al ${ }^{(45)}$ recorded that providing music during hemodialysis is an effective complementary therapy to relieve the frequency and severity of adverse reactions, as well as to lower salivary cortisol levels. Besides, Shaji John et al (46) found that there was a significant decrease in salivary cortisol levels in participants after music training.

This decrease in salivary cortisol secretion as recorded in our study may be due to reduced secretion of ACTH from the pituitary or decreased secretion of cortisol from the adrenal glands due to a reduction in stress and anxiety. ${ }^{(47)}$ It has been suggested in studies that salivary cortisol is one of the reliable physiological markers of stress which is decreased by music via inducing the activity of HPA-Axis. ${ }^{(16,47)}$

Stress is seen as the main threat of health mentally as well as physically. ${ }^{(48)}$ The decrease in stress can reduce this threat and facilitate better well-being of the human body and mental health. (49) This decrease of stress observed in our study might be helpful to facilitate an improved mental state of mind in male medical students as a low level of stress has been found associated with better use of the mental ability. ${ }^{(50)}$ As a response to stress, the endocrine system begins to release cortisol. Therefore a decrease in salivary cortisol marks the decrease in stress and anxiety. ${ }^{(51)}$

Our study recorded a significant decrease in blood pressure after following one month of music therapy. Similar results were shown in a study conducted by Wendy E. K. and Nikki S. ${ }^{(52)}$ Wendy E. L and Nikki S observed that the exposure to music prevented the stressinduced increases in physiological parameters such as subjective anxiety, heart rate and systolic blood pressure in both male and female subjects. This decrease in blood pressure as observed in the present study might be due to music listening evoke some relaxation response which in turn helps in decreasing the blood pressure. ${ }^{(53)}$ Another possible mechanism of action could be that music intervention resulted in heightened brain dopamine levels via a calmodulin-dependent system. This rise in dopamine levels restrained sympathetic activity via dopamine-2 receptors which in turn reduced blood pressure. ${ }^{(54)}$ Besides, it was observed that the heart rate changed to normal post music therapy for a month. This may be due to the reason that classical music tends to relax the body and stimulate the parasympathetic nervous system, thereby changing the abnormal heart rate to normal. ${ }^{(55)}$ It was also perceived that listening to music for a month regulated the respiration rate. Siritunga et al found a similar result in their study. ${ }^{(56)}$ Music acts on the central and autonomic nervous system and the endocrine system sympathetic activity with concurrent activation of parasympathetic drive and a reduction in the stresshormone release, hence regulating the respiration rate. (56) Also, fasting blood sugar levels were seen to improve post music therapy. Madhuri Sharma et $\mathrm{al}^{(57)}$ found related derivation in their previous study. Classical music, a refined sound, stimulates the cell activity in the pancreas and normalizes the blood sugar release, hence reducing the increased blood glucose levels. ${ }^{(58)}$ 
A reduction in triglyceride, LDL with an increase in HDL concluded that music therapy lowers blood lipid levels. This finding was consistent with the results of the previous study conducted by Madhuri Sharma et al. (57) However, the reasons for such an effect of classical music on the lipid profile is unknown.

\section{Conclusion}

Findings of the present study suggest that salivary cortisol, anxiety, depression and stress level were significantly decreased in male medical students after following music therapy with Indian classical instrumental music (raga) for a month. Moreover, a significant decrease in blood pressure, heart rate and fasting blood sugar levels were recorded after music therapy. Therefore, we strongly suggest music therapy for medical students suffering from stress and anxiety to decrease the stress level and enhancing mental health. However, further studies on a larger population are required to make a general policy to facilitate the better mental health of medical students.

Acknowledgement: We are grateful to the Head of Department of Physiology, Rajkiya Medical College, Jalaun, Orai, for the support to the study. We are also thankful to the staff and the subjects for their cooperation.

Conflict of Interest: We certify that there is no conflict of interest.

Ethical Clearance: The Ethical clearance was taken from the ethical committee of Rama Medical College, Hospital \& Research Center, Kanpur, Uttar Pradesh

Source of Funding: No funds were required in this study.

\section{References}

1. Trivedi JK, Gupta PK. An overview of Indian research in anxiety disorders. Indian J Psychiatry. 2010;52(Suppl 1): S210-S218.

2. Mannapur B, Dorle AS, Hiremath LD, Ghattargi CH, Ramadurg U, Kulkarni KR. A study of psychological stress in undergraduate medical students at S N Medical College, Bagalkot, Karnataka. Journal of Clinical and Diagnostic Research. 2010;4:2869-2874.

3. Cohen S, Schwartz JE, Epel E, Kirschbaum C, Sidney S, Seeman T. Socioeconomic Status, Race, and Diurnal Cortisol Decline in the Coronary Artery
Risk Development in Young Adults (CARDIA) Study. Psychosomatic Medicine; 2006;68(1):4150.

4. O'Keefe JH, Poston WS, Haddock CK, Moe RM, Harris W. Psychosocial stress and cardiovascular disease: how to heal a broken heart. Comprehensive Therapy; 2004;30(1):37-43.

5. Reiche EV, Morimoto HK, Nunes SV. Stress and depression-induced immune dysfunction: Implications for the development and progression of cancer. International Review of Psychiatry; 2005;17(6):515-527.

6. Linden W, Moseley JV.The efficacy of behavioral treatments for hypertension. Appl Psychophysiol Biofeedback; 2006;31:51-63.

7. Torpy JM, Burke AE, Glass RM. Acute Emotional Stress and the Heart. Journal of the American Medical Association; 2007;298(3):360.

8. Suess W, Alexander A, Smith D, Sweeney H, Marion R. The Effects of Psychological Stress on Respiration: A Preliminary Study of Anxiety and Hyperventilation. Psychophysiology; 2007;17:535 $-540$.

9. Takai N, Yamaguchi M, Aragaki T, Eto K, Uchihashi K, Nishikawa Y.. Effect of psychological stress on the salivary cortisol and amylase levels in healthy young adults. Arch Oral Bioll; 2004;49:963-8.

10. Jena SK, Misra A, Mohanty A. Effect of examination stress on blood sugar in medical students. CHRISMED Journal of Health and Research; 2016;3:268-272.

11. Assadi SN. What are the effects of psychological stress and physical work on blood lipid profiles? Medicine;2017;96:549 - 64.

12. Ghosal K, Behera A. Study on the prevalence of stress in medical students, J Res Med Dent Sci; 2018;6(5):182-18

13. Compton MT, Carrera J, Frank E. Stress and depressive symptoms/dysphoria among US medical students: results from a large, nationally representative survey. J Nerv Ment Dis; 2008;196:891-897.

14. Hill MR, Goicochea S, Merlo LJ. In their own words: stressors facing medical students in the millennial generation. Medical Education Online; 2018;23:443 - 10 .

15. Bhattacharya S, Chakrabarty $\mathrm{D}$, Bhattacharya 
DK, Chowdhury A. Predictors of Stress, Anxiety, and Depression among Undergraduate Medical Students: A Scenario in a Medical College of Kolkata, IOSR Journal of Dental and Medical Sciences; 2017;16:10-12.

16. Thoma MV, la Marca R, Brönnimann R, Finkel L, Ehlert U, NaterUM. The effect ofmusic on the human stress response. PLoS ONE;2013;8(8):Article e70156.

17. Kotwal MR, Rinchhen CZ, Ringe VV. Stress reduction through listening to Indian classical music during gastroscopy. Diagn Ther Endosc; 1998;4(4):191-197.

18. Nagarajan K, Srinivasan TM, Ramarao NH. The immediate effect of listening to Indian raga on attention and concentration in healthy college students: A comparative study. J Health Res Rev 2015;2:103-7.

19. Singh M, Bhatnagar P. Anxiety Depression Stress Scale (ADSS): A Factor Analytic Study. International Journal of Indian Psychology; 2016;3 (2).

20. Edwards S, Clow A, Evans A, Hucklebridge F. Exploration of the awakening cortisol response concerning diurnal cortisol secretory activity. Life Sci; 2001;68:2093-2103.

21. Nater UM, Rohleder N, Schlotz W, Ehlert U, Kirschbaum C. Determinants of the diurnal course of salivary alpha-amylase. Psycho neuroendocrinology; 2007;32:392-401.

22. Sarkar J, Biswas U. Indian classical ragas to cure diseases. International Journal of Advanced Science and Research; January 2015;1(1):09-13.

23. Gupta U, Gupta BS. Psychophysiological responsivity to Indian Instrumental music. Psychology of Music; 2005;33(4):363-372

24. Kreutz G, Bongard S, Rihrmann S, Hodapp V, Grebe D. Effects of Choir Singing or Listening on Secretory Immunoglobulin A, Cortisol, and Emotional State. Journal of Behavioral Medicine. December 2004, 27 (6), pp 623-635

25. Kumar P, Clerk M. Clinical medicine: A textbook for medical students and doctors. 4th Edition, W.B.aunders, Edinburgh;2001.

26. Pritchard BT, Stanton W, Lord R, Petocz P, Pepping GJ. Factors Affecting Measurement of Salivary Cortisol and Secretory Immunoglobulin A in Field Studies of Athletes. Front Endocrinol (Lausanne).
2017;8:168. Published 2017 Jul 24.

27. Ogedegbe G, Pickering T. Principles and techniques of blood pressure measurement. Cardiol Clin. 2010 Nov; 28(4):571-86.

28. Pickering D. How to measure the pulse. Community Eye Health. 2013;26(82):37.

29. Michel S. Hutchison's clinical method. 20th Edition, Saunders Company, London;1995.

30. Kumar A, Sharma AK, Mittal S, Kumar G. The Relationship Between Body Mass Index and Bone Mineral Density in Premenopausal and Postmenopausal North Indian Women. J Obstet Gynaecol India. 2016;66(1):52-56.

31. Validation of the Friedewald Formula in Patients with Metabolic Syndrome;2014;261878:5 pages,

32. Selye, H. A syndrome produced by diverse nocuous agents. Nature; 1936;138:32.

33. Journal of Extension: a personal message from Hans Selye; May/June 1980.

34. Lazarus RS, Folkman S. Stress, Appraisal, and Coping. New York: Springer;1984.

35. Trivedi JK, Gupta PK. An overview of Indian research in anxiety disorders. Indian J Psychiatry. 2010;52(Suppl 1):210-218.

36. Babu RD, Nirmala C, Shashikala V; A Study To Assess the Prevalence of Depressive And Anxiety Symptoms Among Higher Secondary Students. IOSR Journal of Dental and Medical Sciences (IOSR-JDMS);Aug. 2017;16(8):49-57.

37. Weiller E, Bisserbe JC, Maier W, Lecrubier Y. Prevalence and recognition of anxiety syndromes in five European primary care settings. A report from the WHO study on Psychological Problems in General Health Care. Br. J. Psychiatry Suppl. 1998;34:18-23.

38. Kroenke K., Spitzer R.L., Williams J.B., Monahan P.O., Lowe B. Anxiety disorders in primary care: Prevalence, impairment, comorbidity, and detection. Ann. Intern. Med. 2007;146:317-325.

39. Sarkar S, Gupta R, Menon V. A systematic review of depression, anxiety, and stress among medical students in India. J Mental Health Hum Behav 2017;22:88-96.

40. Taneja N, Sachdeva S, Dwivedi N. Assessment of depression, anxiety, and stress among medical students enrolled in a medical college of New Delhi, India. Indian J Soc Psychiatry 2018;34:157- 
62.

41. Jayakrishnan T, Honhar M, Jolly GP, Abraham J, T J. Medical education in India: Time to make some changes. Natl Med J India 2012;25:164-7.

42. Pruthi S, Pandey R, Singh S, Aggarwal A, Ramavat A, Goel A, et al. Why does an undergraduate student choose medicine as a career. Natl Med J India 2013;26:147-9.

43. Barriers to healthcare seeking among medical students: A cross-sectional study from South India. Menon V, Sarkar S, Kumar S. Postgrad Med J. 2015;91:477-482.

44. Kamli P, Saini S, Effectiveness of yoga on anxiety, depression and stress level of breast cancer patients undergoing chemotherapy, International Journal of Research in Medical Sciences; Int J Res Med Sci. 2018 Jan;6(1):74-81.

45. Hou YC, Lin YJ, Lu KC, Chiang HS, Chang CC, Yang LK. Music therapy-induced changes in salivary cortisol levels are predictive of cardiovascular mortality in patients under maintenance hemodialysis. Ther Clin Risk Manag. 2017;13:263-272.

46. Kachanathu S, Verma S, Khanna G. The effect of music therapy on salivary cortisol as a reliable marker for pre-competition stress in shooting performance. Journal of Exercise Science \& Physiotherapy;2010;4:16-23.

47. David A. Wilson, Clinical Veterinary Advisor, W.B. Saunders 2012, Pages 922-923,

48. Kinman G, Jones F. Lay representations of workplace stress: What do people really mean when they say they are stressed? Work and Stress. 2005; 19(2): 84-102.

49. Shahsavarani, A., Azad Marz Abadi, E., Hakimi Kalkhoran, M. Stress: Facts and Theories through Literature Review. International Journal of Medical Reviews, 2015; 2(2): 230-241.
50. Schneiderman N, Ironson G, Siegel SD. Stress and health: psychological, behavioral, and biological determinants. Annu Rev Clin Psychol. 2005;1:607628.

51. Tsigos C, Kyrou I, Kassi E, Chrousos GP. Stress, Endocrine Physiology and Pathophysiology. In: Endotext. MDText.com, Inc., South Dartmouth (MA); 2000.

52. Knight WE, Rickard NS. Relaxing music prevents stress-induced increases in subjective anxiety, systolic blood pressure, and heart rate in healthy males and females. Journal of Music Therapy; 2001;38(4):254 - 272.

53. Kühlmann AYR, Etnel JRG, Roos-Hesselink JW et al. Systematic review and meta-analysis of music interventions in hypertension treatment: a quest for answers. BMC Cardiovasc Disord; 2016;16:69.

54. Sutoo D, Akiyama K. Music improves dopaminergic neurotransmission: demonstration based on the effect of music on blood pressure regulation. Brain Res. 2004;1016(2):255-62.

55. Chuang CY, Han WR, Li PC, Song MY, Young ST. Effect of Long-Term Music Therapy Intervention on Autonomic Function in Anthracycline-Treated Breast Cancer Patients. Integrat Cancer Ther. 2011;10(4):312-6.

56. Siritunga S, Wijewardena K, Ekanayaka R, Mudunkotuwa P. Effect of music on blood pressure, pulse rate and respiratory rate of asymptomatic individuals: A randomized controlled trial. Health.2013;05:59-64.

57. Sharma M, Rajnee D, Mathur K. Effects Of Music Therapy On Clinical And Biochemical Parameters Of Metabolic Syndrome. Journal of Bangladesh Society of Physiologist; 2011 December;6(2):108-115.

58. Edward P, Music for Your Health. New York: Bernard Ackerman, Inc.1945;26-27. 